DOI: $\underline{10.20472 / T E .2015 .3 .1 .006 ~}$

\title{
STUDENTS' GRAMMAR MISTAKES AND EFFECTIVE TEACHING STRATEGIES
}

\author{
KRISTA UIBU, MERILI LIIVER
}

\begin{abstract}
:
In order to prevent grammar mistakes different teaching strategies are recommended. The aim of this study was to find out what are the causes of grammar mistakes, what practices teachers use to correct students' mistakes and which strategies are considered to be the most effective to prevent students' mistakes. Twenty-five Estonian language teachers were asked to describe their teaching and prevention strategies. The quantitative content analysis indicated three types of teachers. Teachers with a deductive profile were considered to be the most efficient in supporting students' recalling and remembering skills. Teachers with inductive or combined teaching profiles used more examples and diverse strategies. By using the effective teaching strategies, teachers are able to better support students' language development and individual peculiarities.
\end{abstract}

\section{Keywords:}

grammar mistakes, native language, deductive and inductive teaching, effective strategies, basic school

\section{Authors:}

KRISTA UIBU, Institute of Educational Sciences, University of Tartu, Estonia, Email: krista.uibu@ut.ee MERILI LIIVER, University of Tartu, Estonia, Email: merilili@hot.ee

\section{Citation:}

KRISTA UIBU, MERILI LIIVER (2015). Students' Grammar Mistakes and Effective Teaching Strategies. International Journal of Teaching and Education, Vol. III(1), pp. 70-87., 10.20472/TE.2015.3.1.006 


\section{Introduction}

Writing process involves compilation of texts as well as orthography and grammar. The right meaning of words, grammatically correct spelling and correct syntax and grammar contractions must be acquired in order to attain a good penmanship (Cain and Oakhill, 2007: 41-76). Learning grammar, especially the use of punctuation marks is one of the most difficult tasks for students. This is confirmed by international comparative studies (e.g., OECD 2009, 2013) and the result of national academic placement tests in the native language (Sinka, 2009; Vardja, 2008).

By the end of basic school students must be familiar with the phonetic system of the language, the basis of orthography and be able to follow the basic rules covered at school (The National Curriculum for Basic Schools, 2010). Students have to construct proper sentences and use punctuation marks in simple and easier compound sentences, as well as apply this knowledge when creating texts. A variety of language teaching practices and strategies must be used to improve students' penmanship (Uibu and Männamaa, 2014: 96-131). Different ways of individual work or cooperative learning should be used depending on the topic and goal of teaching (Entwistle, 1998: 225-258). The general trend prevailing currently in language teaching is to move from teachercentred teaching to student-centred learning where the teacher encourages analysis and creativity (Mattarima and Hamdan, 2011: 238-248). On the contrary to the deductive learning which proceeds from the principle that at first students get acquainted with language rules followed by explanatory examples and exercises, the inductive approach starts with presenting examples and a student formulates a rule on the basis of these examples (Thornbury, 1999).

The aim of this study is to ascertain how native language teachers explain mistakes in orthography, syntax and determination of the sentences' purpose of communication in students' texts and what practices they use to correct these mistakes. The study also analyses the strategies that teachers consider effective in preventing students' grammar mistakes. It also looks into the differences in opinions on effective language teaching strategies of teachers with different teaching experience.

\section{The acquisition of grammar and cognitive skills}

Grammar is a set of rules that explores the forms and structures of sentences that can be used in a language (Gleason and Ratner, 2009: 231-269; Thornbury, 1999). There are two important concepts related to grammar: morphology that studies the formation of words, their structure and relationships between them, and syntax that studies the structure of sentences, relations between sentence units, the internal structure of phrases and relations between them that gives meaning to sentences (Saxton, 2010: 51-66; Thornbury, 1999). 
The studies of acquisition of grammar have shown that one of the main preconditions for learning and mastering grammatical categories is to understand the relations between language units (Saxton, 2010: 51-66; Hedge, 2000; Thornbury, 1999). In order to do that the acquired information must be preserved and used (Skehan, 2008: 13-27). The speed and time of acquisition depend on the complexity of the language category and the frequency of its use. However, developers of native language teaching argue that by paying too much attention to teaching grammar (especially in primary schools) the development of child' writing skills may be hindered (Uusen and Müürsepp, 2010: 170184).

The acquisition of grammar is first of all related to cognitive skills (Krathwohl, 2002: 212-218; Tiene and Ingram, 2001: 58-90). Lower level cognitive skills (e.g. attentiveness, remembering) are important in language learning as they help to learn and recall language rules. The main problems at that level are related to learning rules wrongly and using the acquired information incorrectly (Uibu and Tropp, 2013: 45-63; Mayer, 2002: 227-232). Medium level cognitive skills (e.g. comprehension, the use of knowledge in appropriate situations) involve understanding language rules and their application in different situations (Tiene and Ingram, 2001: 58-90). Students tend to acquire lots of facts easily but they often do not understand what is behind them (Hills, 2004: 57-64; Mayer, 2002: 227-232).

Analysis, synthesis and evaluation need higher level cognitive skills (e.g. generalisation, extrapolation). The tasks presuming these skills require that students understand, reason or evaluate situations (Krathwohl, 2002: 212-218). Students must be able to presume and resolve problems in an original manner (Mayer, 2002: 227-232). A student with good analysis and synthesis skills is able to divide the material into components, deduce and make conclusions. Such a student is also capable of connecting separate components into a whole and conclude them. Studies confirm that there are hierarchic relations between cognitive levels and that without understanding the meaning of factual knowledge it is impossible to apply, analyse, synthesise and evaluate it (see Krathwohl, 2002: 212-218; Tiene and Ingram, 2001: 58-90). Grammar mistakes are generally caused by problems related to students' cognitive skills and their individual traits (Mayer, 2002: 227-232). Mistakes may also be caused by language teaching strategies used by a teacher (Thornbury, 1999; Uibu and Männamaa, 2014: 96-131).

\section{Students' grammar mistakes and language teaching strategies}

All language learners make mistakes. If mistakes occur it is important to pay attention to their type and reason why they have occurred. It is also important to analyse different ways to prevent mistakes (Thornbury, 1999). Errors may emerge at the level of single words (e.g. in orthography where affixes, vowel and consonant clusters and inflected forms play an important role). As to the sentence level the problems related to the 
sequence of words and punctuation marks, and linking simple sentences into compound sentences are the most frequent ones. Discourse mistakes are caused by errors made while connecting sentences and associating them with the rest of the text (Sinka, 2009; Thornbury, 1999).

Grammatical correctness of language use becomes topical when children go to school (Skehan, 2008: 13-27; Widodo, 2006: 27-38) where different strategies are used to teach languages. The choice of strategies is found to be dependent on student's learning motivation, self-esteem and individual characteristics (Jinping, 2005: 90-94; Mayer, 2002: 227-232). The choice of the appropriate strategy has also been found to ensure success in further language learning as it helps to learn a language more effectively (Thornbury, 1999).

According to several authors (Egel, 2009: 2023-2026; Griffiths, 2009; Skehan, 2008: 13-27) effective language teaching strategies support the instructional goals, involve students in the process of learning and develop their problem resolving skills. Inductive teaching and different forms of group-works are suitable for these purposes (Entwistle, 1998: 225-258; Thornbury, 1999). The choice of teaching strategies also depends on the previous teaching experience. Studies have shown that more experienced teachers use a more deductive approach, i.e. traditional teaching strategies. Less experienced teachers are not as aware and they tend to prefer integrated strategies (Uibu and Kikas, 2014: 522).

Deductive and inductive teaching strategies. Language rules are often complicated and their interpretations may be contradictory (Uusen and Müürsepp, 2010: 170-184). In the case of deductive teaching, which has prevailed for a long time in teaching grammar, rules are presented in a ready-made form. In the case of inductive teaching language rules are derived from the context. In other words, an inductive approach is based on examples and discovery, while a deductive approach is based on rules (Xio-Yun, 2008). The question is how much attention should be paid in language teaching to learning rules and how much room should be left for discovering them by students (Skehan, 2008: 13-27).

Deductive teaching of grammar has lately received quite a lot of negative attention (Allahyar and Ramezanpour, 2011: 240-243). A typical lesson following that approach starts with explaining the rule which is followed by practicing exercises. During the completion of exercises the focus is mainly on reading and writing, while self-expression may be completely neglected. Besides, if the lesson is started with grammar it may cause a certain unwillingness in pupils, especially in younger ones. This sort of teaching embeds the idea that language learning is based only on remembering rules (DeFelice, 2005: 49-51; Thornbury, 1999). The positive aspect of the method is that it saves time. Teacher's explanations, independent work and subsequent checks are effective methods for learning facts and developing basic skills (Allahyar and Ramezanpour, 2011: 240- 
243; Entwistle, 1998: 225-258). This sort of teaching has been found suitable for many students (Thornbury, 1999; Widodo, 2006: 27-38).

Inductive teaching of grammar means that the students have no previous knowledge of a rule and they learn it by studying examples of it. The learning process is almost hidden as students are reading the text which includes the grammar form to be learnt but their attention is focused on the text or activity and not on the grammar (Gleason and Ratner, 2009: 231-269). Inductive teaching means that a teacher helps a student to learn and practice the language but does not emphasise the grammar. Students use the language in its natural context and acquire it subconsciously (Skehan, 2008: 13-27). The weakness of the inductive teaching method lies in the fact that formulating a rule takes a lot of time and there is little time left for exercising it (Thornbury, 1999). Besides, a pupil may interpret the rule wrongly by extending it to examples to which it does not apply or sometimes it is impossible to formulate the rule on the basis of example (Allahyar and Ramezanpour, 2011: 240-243; Thornbury, 1999). Inductive teaching is found to be difficult for students who value definite concepts and who are not very creative (Allahyar and Ramezanpour, 2011: 240-243). However, teaching on the basis of examples develops skills necessary for the ability of expression and communication (Schmid and Kitzelmann, 2011: 237-248). Besides, it has been found that if the students formulate a rule by themselves they will remember it better and it has greater meaning for them (Thornbury, 1999). During intellectual efforts cognitive abilities prevail which ensures better remembering (Widodo, 2006: 27-38).

\section{Correcting grammar mistakes of students}

Studies show that ignoring mistakes may jeopardise the linguistic development of students (Thornbury, 1999; Woods, 1997: 8-9). It is important to pay attention to the manner of reacting to grammar mistakes that have occurred. A teacher has to identify the type of mistake and decide whether it is important to correct it, when to correct it and which strategy to use for it (Entwistle, 1998: 225-258).

Contemporary language methodologies are generally quite tolerant about mistakes. Many teachers consider positive feedback important and provide students with it when they are right. However, they do not point out students' mistakes (Uusen and Müürsepp, 2010: 170-184). Thus, the linguistic development of students may be inhibited because most of the feedback is complimentary and they do not have realistic knowledge about the amount of mistakes they make. Therefore, it is important to react effectively to mistakes by paying attention even to those which may initially seem irrelevant (Woods, 1997: 8-9). Negative feedback should not be too harsh because this may establish the habit to use the incorrect form (Thornbury, 1999). 
Another recognised technique used in language teaching is to guide students in the manner that they find their own mistakes. If the children have an interest in, and proficiency for, writing it is possible to teach them to find and analyse grammar mistakes (Uusen and Müürsepp, 2010: 170-184). A teacher does not correct the mistake but draws a students' attention to it and gives them the opportunity to correct it (Allahyar and Ramezanpour, 2011: 240-243).

\section{The aims and hypotheses}

The acquisition of orthography has always been one of the most complicated tasks (Saxton, 2010: 51). The aim of this study was to find out the opinion of Estonian language teachers on the reasons for mistakes the basic school students make in orthography, syntax and determination of sentence type. Also, the practices and strategies used by teachers to correct and prevent grammar mistakes were analysed. Proceedingrom that four research goals were formulated.

1. There are different reasons for grammar mistakes. The lack of cognitive skills of students is considered as the main one (Krathwohl, 2002: 212-218; Mayer, 2002: 227-232). In order to avoid mistakes it is important to understand the reasons for them. The study identifies the opinions of Estonian language teachers on the most frequent grammar mistakes related to orthography, syntax and the determination of the sentence type according to its purpose of communication.

2. Studies have shown that deductive (based on a rule) as well as inductive (based on examples) strategy of teaching are used when teaching foreign languages but when it comes to teaching a native language deductive teaching prevails (Saxton, 2010: 51-66; Hedge, 2000). Teachers tend to use practices that support the development of different cognitive skills of students (Entwistle, 1998: 225-258). The study analyses the practices used by teachers to correct different type of grammar mistakes.

3. Those teaching strategies that support the improvement of students' higher level cognitive skills are considered as effective (Mayer, 2002: 227-232; Slavich and Zimbardo, 2012: 569-608). Therefore, the practices that require skills to analyse and resolve problems should be used (Thornbury, 1999; Uibu and Kikas, 2014: 522). An answer is sought for the question as to which strategies are considered effective by teachers for the prevention of students' mistakes in orthography, syntax and determination of the right type of sentence according to its purpose of communication.

4. Different teaching strategies are suitable for the development of different constituent skills (Allahyar and Ramezanpour, 2011: 240-243; Thornbury, 1999). The use of appropriate strategies supports the goals of language teaching and makes learning more effective (Entwistle, 1998: 225-258). The study analyses the 
opinions of teachers with different practice profiles on effective strategies for the prevention of orthographic, syntax and determination of correct sentence type mistakes made by students. The differences between teachers profile groups based on their teaching experience are also compared.

\section{Method}

\section{Sample and procedure}

Twenty-five Estonian language teachers from 17 schools participated in the study. The teachers were chosen on the basis of the location of schools (rural and urban areas), type of schools (basic and secondary schools) and sizes of the classes they taught (smaller and larger classes). The number of students in classes where teachers taught the Estonian language varied. The sample consisted of 19 women and one man. Two teachers did not specify their gender. All teachers taught Estonian in the seventh form. Twenty respondents marked the Estonian language and literature as their speciality, one of the respondents had graduated as a specialist in special needs education and one respondent had learnt the Estonian language and literature together with another humanitarian subject. The teaching experience of teachers varied from 2 to 38 years $(\mathrm{M}=$ $18.00, S D=11.42$ ). Three teachers did not mention their teaching experience. Teachers were divided according to their teaching experience into four groups based on Dreyfus' model (Dreyfus, 1981): beginners (teaching experience $\leq 5$ years; 4 teachers), advanced (6-10 years; 7 teachers), competent (11-20 years; 6 teachers) and experts ( $\geq 21$ years; 9 teachers).

The data was gathered within the framework of the larger project where teachers filled out the electronic form of an open-ended questionnaire via the Internet.

\section{Questionnaire}

In order to ascertain the opinion and assessment of teachers on the reasons for mistakes students make in their native language and on the strategies used to prevent these mistakes a Teaching practices questionnaire (TPQ) consisting of nine open-ended questions was used. First, the three most frequent mistakes of orthography, syntax and determination of the sentence type according to the purpose of communication were selected from the students' language test. The teachers were asked to have a say on the possible reasons for each type of mistake, i.e. why could a student give the specific wrong answer. Secondly, the teachers were asked to describe in written form how they correct the grammar mistakes, occurring in students' language tests (i.e. spelling of consonant clusters, using commas in simple sentences, using interrogative sentences not 
only for asking something but also for expressing wishes and requests). Thirdly, the teachers described which strategies they find to be effective in preventing these mistakes. To this end, two open-ended questions were designed for each type of language mistakes, i.e. How do you correct this type of mistake? How one should prevent students from making this type of mistakes? These questions allowed the teachers to describe openly their teaching practices and beliefs in effective strategies in prevention of language mistakes.

\section{Data analysis}

1. Quantitative content analysis. The teachers' responses to the open-ended questions were analysed using the method of quantitative content analysis (Cohen, Manion, and Morrison, 2007: 470-473). In order to ensure the reliability of the study double coding was used. All units - words, concepts and occurrences - connected to the teachers' teaching practices or their beliefs in effective strategies in prevention of language mistakes were coded by the both authors. In the first stage of coding the data given by teachers was analysed inductively, by discussing jointly $10 \%$ of the responses given by teachers. A code was given to each answer. Initially the number of codes was very large. However, during discussions their denominations were unified. During the second stage of decoding teachers' answers were decoded independently from each other following the respective theory. There were some controversial and unclear descriptions which were reanalyzed together. The subjects, on the basis of which data was categorised, narrowed. The results of quantitative content analysis were reported in tabular form.

The similar codes were placed into categories, separately for three grammar tasks. The categories were defined on the basis of theoretical meaningfulness (Krathwohl, 2002: 212-218; Mayer, 2002: 227-232): promotion of (1) students' lower-order thinking skills (e.g., knowing, recalling), (2) application, comprehension and problems solving skills, (3) higher-order thinking skills (e.g., analyzing, reasoning). Also, different combinations of these cognitive process categories were determined. The final labels were developed together by the authors. The teacher's individual scores were counted separately for each grammar task. Inter-observers reliability between two coders was calculated. The agreement rate (Cohen's Kappa) for variables was excellent, ranging from .76 to .94 by categories.

2. Statistics. The data was analysed by the statistics package SPSS Statistics, version 20.0. Descriptive analyses were carried out to compare teachers' comprehension about the reasons for grammar mistakes students make, teacher's practices on correcting these mistakes and effective strategies to prevent grammar mistakes. To ascertain the differences between the estimations of teachers with different teaching profiles on 
effective language teaching strategies a cross-tabulation was used. The distribution of teachers in profile groups by their teaching experience was analysed by the $X^{2}$-test.

\section{Results}

\section{Students' grammar mistakes and teachers' correction practices}

Descriptive analyses were carried out to ascertain teachers' notions on the reasons for students' Estonian language grammar mistakes (orthography, syntax and determination of the sentence type according to the purpose of communication). The results of the frequency analysis are presented in table 1.

Table 1. Teachers' understanding on the reasons for grammar mistakes.

\begin{tabular}{|c|c|c|c|}
\hline & \multicolumn{3}{|c|}{ Grammar mistakes } \\
\hline & $\begin{array}{l}\text { Orthography } \\
(\mathrm{N}=25)\end{array}$ & $\begin{array}{l}\text { Syntax } \\
(N=22)\end{array}$ & $\begin{array}{l}\text { Sentence's purpose } \\
\text { of communication } \\
(\mathrm{N}=22)\end{array}$ \\
\hline 1 (Mis)conception & 3 & 22 & 14 \\
\hline 2 Remembering & 11 & 1 & 1 \\
\hline 3 Comprehension & 13 & 0 & 2 \\
\hline 4 Thinking & 6 & 0 & 3 \\
\hline 5 Inattentiveness & 3 & 0 & 2 \\
\hline 6 Analysis & 0 & 16 & 0 \\
\hline 7 Absorption & 0 & 0 & 9 \\
\hline
\end{tabular}

It appeared that teachers were of the opinion that all types of mistakes were caused by the lack of students' cognitive skills. Teachers pointed out seven reasons for mistakes made in orthography $(M=2.77, S D=.82)$, three in syntax $(M=1.77, S D=.43)$ and six reasons for mistakes related to the determination of correct sentence type $(M=1.41, S D$ $=.50)$. Misconception and remembering incorrectly by students were repeatedly emphasised reasons for all types of mistakes. The most frequently mentioned reasons for orthographic mistakes were related to problems with understanding and remembering. As to the mistakes related to syntax misconception and lack of analytical skills were mentioned most frequently. In addition, misconception and inattentiveness were the most frequently mentioned reasons for mistakes related to the determination of sentence type according to its purpose of communication.

After that, the practices that teachers would use if the students in their class had made the same mistakes related to orthography, syntax and determination of sentence type than presented in the questions were analysed (see Table 2). 
Table 2. Teachers' correction practices.

\begin{tabular}{llll}
\hline \multirow{2}{*}{ Teaching practices } & \multicolumn{3}{l}{ Grammar mistakes } \\
\cline { 2 - 4 } & $\begin{array}{l}\text { Orthography } \\
(\mathrm{N}=22)\end{array}$ & $\begin{array}{l}\text { Syntax } \\
(\mathrm{N}=22)\end{array}$ & $\begin{array}{l}\text { Sentence's purpose } \\
\text { of communication } \\
(\mathrm{N}=22)\end{array}$ \\
\hline 1 Analysis & 2 & 8 & 9 \\
2 Repeating & 6 & 5 & 3 \\
3 Explaining & 7 & 6 & 1 \\
4 Illustrating & 9 & 3 & 2 \\
5 Recalling & 3 & 5 & 0 \\
6 Application & 0 & 5 & 3 \\
7 Discussion & 1 & 0 & 7 \\
8 Comprehension & 0 & 7 & 1 \\
9 Reasoning & 0 & 2 & 2 \\
10 Comparing & 0 & 0 & 5 \\
11 Re-phrasing & 3 & 0 & 0 \\
\hline
\end{tabular}

Teachers named 11 activities focusing on the development of students' cognitive development that would, in their opinion, help to correct grammar mistakes. Teachers pointed out 8 practices related to syntax $(M=1.86, S D=.83), 7$ practices related to orthography $(M=1.55, S D=.51), 9$ practices related to the determination of the sentence type according to its purpose of communication $(\mathrm{M}=1.55$, $\mathrm{SD}=.86)$. Illustrating, explaining and repeating were considered to be the most common practices to prevent orthographic mistakes. As for correcting mistakes related to syntax and determination of the correct type of sentence teachers considered analysis as the most effective measure (8 and 9 times, respectively). Besides that, the development of understanding was considered an important measure related to correcting syntax mistakes and as to the determination of sentence type according to its purpose of communication the discussion carried out with students was given a high value (both 7 times).

Next, the analysis of practices and strategies considered by teachers as effective in preventing students' grammar mistakes was carried out (Table 3). 
Table 3. Teachers' opinion on effective strategies to prevent grammar mistakes.

\begin{tabular}{|c|c|c|c|}
\hline \multirow[b]{2}{*}{$\begin{array}{l}\text { Effective teaching } \\
\text { and strategies }\end{array}$} & \multicolumn{2}{|c|}{ Grammar mistakes } & \multirow[b]{2}{*}{$\begin{array}{l}\text { Sentence's purpose } \\
\text { of communication }\end{array}$} \\
\hline & Orthography & Syntax & \\
\hline \multicolumn{4}{|l|}{ I. Teaching practices } \\
\hline 1 Repeating & 15 & 10 & 6 \\
\hline 2 Illustrating & 5 & 5 & 11 \\
\hline 3 Explanation & 6 & 2 & 4 \\
\hline 4 Comprehension & 1 & 4 & 2 \\
\hline 5 Analysis & 1 & 3 & 2 \\
\hline 6 Recalling & 3 & 2 & 1 \\
\hline 7 Understanding & 1 & 4 & 0 \\
\hline 8 Re-phrasing & 3 & 0 & 0 \\
\hline 9 Discussion & 0 & 0 & 3 \\
\hline 10 Application & 0 & 3 & 0 \\
\hline \multicolumn{4}{|l|}{ II. Language strategies } \\
\hline 1 Inductive teaching & 8 & 6 & 8 \\
\hline 2 Deductive teaching & 9 & 3 & 2 \\
\hline
\end{tabular}

In order to prevent orthography and syntax mistakes teachers pointed out 8 strategies focusing on the development of students' cognitive skills $(M=1.71, S D=.46$ and $M=$ $1.70, S D=.66$, respectively). For the prevention of mistakes related to the determination of sentence type, according to its purpose of communication, 7 strategies were suggested $(M=1.65, S D=.67)$. According to the teachers' opinion the best results are received by repeating and illustrating, no matter what type of mistakes are involved.

\section{Effective prevention strategies by teachers' profiles}

The teachers were initially divided into three groups on the basis of the description of their practices in order to find out whether there are certain patterns in teaching practices preferred by teachers (i.e. substantial profiles) and in what way the opinions of teachers with a different profile on effective language teaching strategies differ from each other. The teachers who did not describe any effective language teaching strategies were left out of the analysis. Fourteen teachers were profiled. The first group consisted of teachers who mentioned inductive teaching methods as a means of correcting at least two types of grammar mistakes (e.g. orthography: not indicated; syntax: inductive; determination of the sentences' purpose of communication: inductive; hereinafter: Inductive profile). The second group consisted of teachers who mentioned deductive teaching as a means of correcting at least two types of grammar mistakes (e.g. orthography: deductive; syntax: deductive; determination of the sentences' purpose of communication: not indicated; 
hereinafter: Deductive profile). The third group of teachers was characterised by the combined approach to correcting mistakes (e.g. orthography: deductive; syntax: inductive; determination of the sentences' purpose of communication: not indicated; hereinafter: Combined profile).

In order to analyse which strategies are considered effective by teachers with different profile cross-tabulation was used. The overview of the results by type of mistakes is presented in table 4.

Table 4. Effective strategies by teachers belonging in different profile groups.

\begin{tabular}{lll} 
Teacher's profiles & & \\
\hline Inductive profile & Deductive profile & Combined \\
$(\mathrm{N}=4)$ & $(\mathrm{N}=4)$ & profile \\
& & $(\mathrm{N}=5)$
\end{tabular}

\begin{tabular}{llll}
\hline I. Orthography & 3 & 3 & 4 \\
1 Repeating & 2 & 1 & 1 \\
2 Illustrating & 2 & 0 & 1 \\
3 Explanation & 0 & 2 & 0 \\
4 Recalling & 0 & 1 & 1 \\
5 Re-phrasing & & & \\
II. Syntax & 2 & 1 & 1 \\
1 Repeating & 2 & 1 & 1 \\
2 Illustrating & 1 & 1 & 0 \\
3 Explanation & 2 & 0 & 0 \\
4 Comprehension & 0 & 2 & 0 \\
5 Recalling & 0 & 1 & 1 \\
6 Application & 0 & 1 & 1 \\
7 Embedding & 1 & 0 & 1 \\
8 Analysis & & & \\
III. Sentences' purpose of & & \\
communication & 1 & 3 & 3 \\
1 Illustrating & 1 & 0 & 1 \\
2 Discussion & 2 & 0 & 0 \\
3 Explanation & 2 & 0 & 0 \\
4 Repeating & 1 & 0 & 0 \\
5 Analysis & 0 & 0 & 1 \\
6 Comprehension & & & \\
\hline
\end{tabular}

It appeared that teachers with Deductive and Combined profiles considered four strategies supporting the development of students' cognitive skills as an effective measure to prevent orthographic mistakes, while teachers with Inductive profile pointed out three strategies like that. Although teachers of all three profile groups were of the 
opinion that repetition would help to prevent grammar mistakes, the teachers with a Deductive profile mentioned first of all repeating and recalling. These practices focus mainly on the development of lower and medium level cognitive skills of students. When the strategies of preventing syntax mistakes of teacher groups with different profiles were compared it came out that again the teachers with a Deductive profile chose recalling more frequently. Teachers with Inductive profile used the widest range of effective practices (5 practises 8 times).

The largest differences between the teachers belonging into different profile groups appeared in preventing mistakes related to sentences' purpose of communication. The most different strategies were described by teachers of the Inductive profile group (5 practices 7 times). Teachers with Deductive profile (3 teachers) considered illustrating as the only effective practice. Teachers belonging into Combined profile group also mentioned illustrating as the most effective practice.

In order to analyse differences in teachers profile groups depending on their teaching experience $x^{2}$-test was carried out. It appeared that statistically there was significantly more advanced teachers in the Combined profile group (6 to 10 years of teaching experience) than in the Deductive profile group, $x^{2}=11.36, p=.02$.

\section{Discussion}

The subject of teaching grammar has often triggered lively discussions (Saxton, 2010: 51-66; Hedge, 2000). It is a complicated topic because there are students for whom this aspect of language learning is unpleasant. The aim of this study was to find out the opinion of Estonian language teachers on the reasons for mistakes students make (e.g. orthography, syntax and determination of the sentence's purpose of communication), what practices teachers use to correct these grammar mistakes and what are the strategies they find effective for preventing them. The opinions of teachers with different profile on effective strategies for preventing grammar mistakes were also compared. It appeared that the shortcomings in cognitive skills of students are considered as the main reason for mistakes. However, when it comes to the choice of a teaching strategy the ones that support lower and medium level cognitive skills of students are preferred and much less attention is paid to the development of higher level cognitive skills. Teachers with an Inductive or Combined teaching profile used more varied teaching strategies than teachers belonging to the group of teachers with Deductive profile.

When the reasons for the grammar mistakes of students were examined it came out that teachers were of the opinion that all types of mistakes - orthography, syntax and determination of the sentence's purpose of communication - were caused by the lack of cognitive skills of students. Mistakes are often caused by deficiencies in lower level cognitive skills such as remembering and recalling (Krathwohl, 2002: 212-218; Mayer, 2002: 227-232). Teachers considered that established misconception was the main 
reason for mistakes in syntax and determination of the sentence's purpose of communication. The most frequently mentioned reasons for orthographic mistakes were related to the problems with understanding and remembering. According to previous studies there are hierarchic relations between different cognitive levels (e.g. knowing, understanding, analysing) (Krathwohl, 2002: 212-218; Tiene and Ingram, 2001: 58-90). If students cannot remember the information or understand its meaning it is difficult to use and analyse it. Weak skills of analysis were considered an important reason for syntax mistakes. Analysis requires a higher level of cognitive skills (Mayer, 2002: 227-232) that are based on lower and medium level skills.

Secondly, teachers' practices related to correcting students' mistakes in orthography, syntax and determination of the sentence's purpose of communication were analysed. Teachers considered the efforts to improve the cognitive skills of students as very important. In case of mistakes in syntax teachers used understanding and analysis, in the case of sentence's purpose of communication mistakes they preferred analysis and discussion. These practices support students' reflection and generating skills (Krathwohl, 2002: 212-218; Mayer, 2002: 227-232). As to orthography mistakes the need for illustration and reasoning was mentioned most often. The efficiency of reasoning was considered better than illustrating as the development of skills of reasoning improves understanding and reduces the likelihood of repeating the mistake in the future (Hills, 2004: 57-64; Mayer, 2002: 227-232). As to giving examples, it is, however, very important that students understand the connections between the examples. Otherwise, the mistakes may recur. In order to avoid that the practices supporting higher level cognitive skills such as generalisation, conclusion and interconnecting should be preferred (Slavich and Zimbardo, 2012: 569-608).

Thirdly, the analysis was carried out on teachers' opinion about effective strategies to prevent grammar mistakes. As regards correcting mistakes related to syntax and sentence's purpose of communication teachers considered repeating and illustrating as the most effective strategies. Repeating, explaining and illustrating were mentioned as the most common actions to prevent orthographic mistakes. According to several authors (Egel, 2009: 2023-2026; Entwistle, 1998: 225-258; Griffiths, 2009) the most effective language teaching strategies are the ones that develop students' creative thinking, problem resolving skills, critical thinking and the ability for independent analysis. However, repeating and illustrating offer students ready-made truths and constant repeating does not support the development of their skills (Hills, 2004: 57-64; Mayer, 2002: 227-232).

The study also showed that teachers were of the opinion that in order to prevent orthographic mistakes it is important to use inductive as well as deductive teaching but in the case of prevention of syntax and determination of sentence type mistakes it is better to use inductive teaching. However, language teaching should not be based only on inductive or deductive strategies because different strategies are suitable for the development of different constituent skills in different languages (Allahyar and 
Ramezanpour, 2011: 240-243). Both teaching strategies have some strengths and some weaknesses (Gleason and Ratner, 2009: 231-269). The key to successful language teaching lies in the skilful merging of inductive and deductive strategies. The best results are achieved by combining these strategies.

The fourth goal of the study was to analyse the opinion of teachers with different teaching profiles on effective language teaching strategies used to prevent grammar mistakes. Apparently teachers of all profile groups - Inductive, Deductive and Combined - considered repetition to be the most effective means of preventing orthographic mistakes. This approach supports most of all the acquisition rules and is connected with mechanical learning and remembering (Allahyar and Ramezanpour, 2011: 240-243). Knowledge can be embedded by repetition but the content of the learnt material may remain vague and such productive skills as comparing, associating and generating will remain unattainable. However, truly effective language teaching practices do develop these skills (Slavich and Zimbardo, 2012: 569-608).

As regards orthographic and syntax mistakes teachers with Deductive profile considered practices supporting the development of lower and medium level cognitive skills (e.g. repeating and recalling) of students as the most effective means of teaching. The variety of practices used by teachers with an Inductive and Combined profile was wider. Teachers with an Inductive profile mentioned more often the practices that support the skills for understanding, explaining and analysis. These skills are useful for the determination of syntax and the right sentence type (Mayer, 2002: 227-232).

The largest differences between the teachers' practices appeared in the area of the determination of sentence type according to its purpose of communication. The teachers with an Inductive profile mentioned the largest variety of strategies they use. Teachers who preferred deductive teaching mentioned only illustrating. This was also considered the most effective practice by teachers with a Combined profile. Teachers with an Inductive profile considered the development of understanding as the most effective means of prevention of all types of grammar mistakes. Previous studies have also shown that inductive teaching offers more opportunities for the development of language skills than deductive teaching (Allahyar and Ramezanpour, 2011: 240-243). Deductive strategies are more suitable for exercising and resolving certain types of tasks (Hills, 2004: 57-64; Mayer, 2002: 227-232).

Comparing the differences between the teachers with different profiles on the basis of their working experience showed that among teachers who preferred combined teaching there were statistically more teachers whose teaching experience was 6 to 10 years than among the teachers who preferred deductive strategy. Teachers who have taught their subject for more than five years have achieved a certain professional competence (Uibu, Kikas, and Tropp, 2011: 91-111) but they still used strategies that do not support the effective development of all language skills and are focusing more on the development of lower and medium level cognitive skills of students. 
The study had some limitations: the number of teachers participating in the study was rather small, especially in profile groups and the study of teachers' opinions was limited only to certain types of mistakes in orthography, syntax and determination of the correct type of sentence. In future the number of participating teachers should be increased and their opinion on a wider range of reasons for grammar mistakes and the practices and strategies for their correction and prevention should be explored. Despite the abovementioned limitations the study can be used for the improvement of strategies of teaching the native language because so far the inductive and deductive approaches have been mainly studied in the context of teaching foreign languages (see Allahyar and Ramezanpour, 2011: 240-243; Thornbury, 1999). Teachers of the native language must be able to identify the reasons for different grammar mistakes and choose the right practises and strategies that help to reduce and prevent them. It is important that the chosen strategies focus more on the development of higher cognitive skills such as synthesizing and evaluation. The strategies that improve students' language and communication skills have an important place next to teaching that proceeds from the tradition based on knowing rules.

\section{Acknowledgement}

This article was supported by the Estonian Ministry of Education and Research (Grant No S10012).

\section{References}

Allahyar, N., and Ramezanpour, S. (2011) 'No Extreme any More, Strike a Balance', Asian Social Science, vol. 7, no. 5, pp. 240-243.

Cain, K., and Oakhill, J. (2007) 'Reading Comprehension Difficulties: Correlates, Causes and Consequences', in Cain, K. and Oakhill J. (eds.) Children's Comprehension Problems in Oral and Written Language: A Cognitive Perspective, New York, London: The Guilford Press.

Cohen, L., Manion, L., and Morrison, K. (eds.) (2007) Research methods in education, $6^{\text {th }}$ edition, London, New York: Routledge.

DeFelice, B. (2005) 'Well-dressed English', English Teaching professional, vol. 1, pp. 49-51.

Dreyfus, S.E. (1981) Four models human situational understanding: inherent limitations on the modelling of business expertise, Berceley: Operations Research Centre, University of California.

Egel, I.P. (2009) 'Learner autonomy in the language classroom: from teacher dependency to learner independency', Procedia Social and Behavioral Sciences, vol. 1, pp. 2023-2026.

Entwistle, N. (1998) Styles of Learning and Teaching, Oxon: David Fulton Publishers.

Gleason, J.B., and Ratner, N.B. (2009) The development of language, $7^{\text {th }}$ edition, Boston: Allyn and Bacon.

Griffiths, D. (2009). Second Language Acquisition. Pedagogic Grammar. Open Distance Learning, 1-33. 
Hegde, T. (2000). Teaching and Learning in the classroom. Oxford Handbook for Language Teachers. Oxford, NewYork: Oxford Universty Press.

Hills, J.A. (2004) 'Better teaching with Deming and Bloom', Quality Progress, vol. 37, no. 3, pp. 57-64.

Jinping, T. (2005) 'Classroom Language Teaching and Students Motivation', CELEA Journal, vol. 28, no. 2, pp. 90-94.

Krathwohl, D.R. (2002) 'A revision of Bloom`s Taxonomy: An Overview', Theory into Practice, vol. 41, no. 4, pp. 212-218.

Mattarima, K., and Hamdan R.H. (2011) 'Understanding Students' Learning Strategies as an Input Context to Design English Classroom Activities', International Journal of Psychological Studies, vol. 3, no. 2, pp. 238-248.

Mayer, R.E. (2002) 'Rote Versus Meaningful Learning', Theory into Practice, vol. 41, no. 4, pp. 227-232.

OECD. (2009) Creating effective teaching and learning environments: First results from TALIS, Paris: OECD Publishing, [Online], Available: http://www.oecd.org/education/school/43023606.pdf

OECD. (2013) 'PISA 2012 Results: Ready to Learn - Students' Engagement, Drive and Self- Beliefs (Volume III), PISA, OECD Publishing, [Online], Available: http://dx.doi.org/10.1787/9789264201170-en

Saxton, M. (2010) Child Language: Acquisition and Development, London: Sage Publication Ltd.

Schmid, U., and Kitzelmann, E. (2011) 'Inductive rule learning on the knowledge level', Cognitive Systems Research, vol. 12, no. 3-4, pp. 237-248.

Sinka, M. (2009) 6. klassi eesti keele 2008. aasta riikliku tasemetöö analüüs, [Online], Available: http://www.ekk.edu.ee/vvfiles/0/6 \%20klassi eesti \%20keele \%20tasemet 366 366\%202008\%20an al 374 374sx.pdf [20 March 2013].

Skehan, P. (2008) A Cognitive Approach to Language Learning, Oxford: Oxford University Press.

Slavich, G.M., and Zimbardo, P.G. (2012) 'Transformational teaching: Theoretical underpinnings, basic principles, and core methods', Educational Psychology Review, vol. 24, pp. 569-608.

'The National Curriculum of Basic Education of Estonia', (2010) ['Põhikooli riiklik õppekava', in Estonian], [Online], Available: https://www.riigiteataja.ee/akt/13273133 [9 July 2014].

Thornbury, S. (1999). How to teach grammar. Harlow: Pearson Education.

Tiene, D., and Ingram, A. (2001) Exploring current issues in educational technology, New York: McGrawHill.

Uibu, K., and Kikas, E. (2014) 'Authoritative and authoritarian-inconsistent teachers' preferences for teaching methods and instructional goals', Education 3-13: International Journal of Primary, Elementary and Early Years Education, vol. 42, no. 1, pp. 5-22.

Uibu, K., Kikas, E., and Tropp, K. (2011) 'Instructional approaches: Differences between kindergarten and primary school teachers', Compare - A Journal of International and Comparative Education, vol. 41, no. 1, pp. 91-111.

Uibu, K., and Männamaa, M. (2014) 'Õpetamistegevused ja õpilaste tekstimõistmine üleminekul esimesest kooliastmest teise astmesse' ['Teaching practices and text comprehension of students during the transition from the first to second stage of school'], Eesti Haridusteaduste Ajakiri/Estonian Journal of Education, vol. 2, no. 1, pp. 96-131, [Online], Available: http://ojs.utlib.ee/index.php/EHA/article/view/eha.2014.2.1.05 [10 May 2014]. 
Uibu, K., and Tropp, K. (2013) 'Longitudinal Study of the Development of Language Competence among the Estonian 4th and 5th Grade Students', in Mikk, J., Luik, P. and Veisson M. (eds.) Change in Teaching and Learning, Frankfurt am Main: Peter Lang Verlag.

Uusen, A., and Müürsepp, M. (2010) 'Orthographic skills and teaching orthography in light of the renewed Estonian language syllabus', Problems of Education in the 21st Century, vol. 21, pp. 170-184.

Vardja, M. (2008) 6. klassi eesti keele riiklik tasemetöö 2006 [Online], Available: http://www.ekk.edu.ee/vvfiles/0/tasemetood 6kl analuusid 2006.pdf [16 July 2014].

Widodo, H. (2006) 'Approaches and procedures for teaching grammar', English Teaching, Practice and Critique, vol. 5, no. 1, pp. 27-38.

Woods, E. (1997) 'The teacher`s role', English Teaching Proffesionals, vol. 1, no. 2, pp. 8-9. 